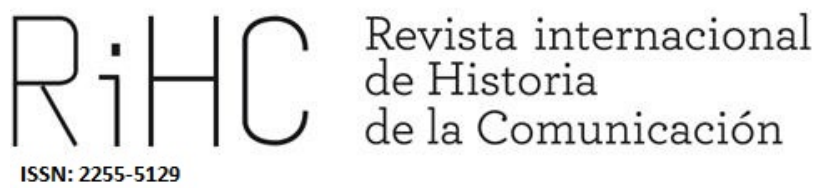

\title{
GÓMEZ DE BLAS, IMPRESOR EN SEVILLA. DE SU VIDA Y TESTAMENTO
}

\section{Gómez de Blas, printer in Seville. About his life and testament}

DOI: http://dx.doi.org/10.12795/RiHC.2018.i10.09

Recibido: 22/04/2018

Aceptado: 01/05/2018

Publicado: $25 / 06 / 2018$

Pilar González Fandos (D) https://orcid.org/0000-0002-7939-9581

Universidad de Sevilla,mpfandos@yahoo.es

Resumen: Juan Gómez de Blas trabaja como impresor en Sevilla de 1633 a 1667. Son 34 años ininterrumpidos publicando información de tipo bélico sobre las contiendas europeas, catalana y portuguesa además de otras noticias, si bien las menos, de carácter fantástico, religioso o directamente relacionadas con la ciudad. Acumuló el privilegio de difundir las disposiciones de los cabildos y algunas órdenes religiosas, trabajo que realizó con una seria periodicidad, lo que sin duda le hizo conocido en la ciudad. Sin embargo, apenas hay testimonios sobre su vida y hemos de hacer este pequeño ejercicio de microhistoria basándonos en la firma que estampó en sus obras y el estudio de su testamento, objeto de este trabajo, que proporciona algunos datos sobre su mentalidad y biografía. 
Palabras clave: Relaciones, opinión pública, censura y leyes, alquiler de viviendas.

\begin{abstract}
Juan Gómez de Blas works as a printer in Sevilla from 1633 to 1667, that is 34 years continuously publishing news about the wars in Europe as well as other events, although in smaller amount, about miracles or directly related to the city. He had the privilege of publishing the dispositions of the Cabildos and some religious orders that he carried out with a serious periodicity, which, no doubt, made him known in the city. However, there are few information about his life and to this little microhistory study we have taken into account the signature of his printed works and his will which has given us some information about his mentality and biography.
\end{abstract}

Keywords: News pamphlets, public opinion, censorship and laws, rental of houses.

\title{
Introducción
}

Relacion del..., relacion de..., solían ser las primeras palabras con las que unas hojillas volanderas, manuscritas o impresas, anunciaban en la primera Edad Moderna los sucesos bélicos, políticos, religiosos o fantásticos. Del inicio tomaron el nombre en España: relaciones. Son los occasionnels de Francia, los news pamphlets ingleses o los neve zeittungen de Alemania... Estamos ante un fenómeno pan-europeo, muy estudiado desde los años 70 del pasado siglo. Estas "hojas volanderas" se incluyen hoy en el campo conceptual de la historia del periodismo lo que hace retroceder su origen en más de un siglo. Díaz Noci (2001) va aún más allá y cita como "un ejemplo enormemente exitoso de incipiente periodismo la carta de Cristóbal Colón anunciando el descubrimiento, cuya edición princeps data de abril de 1493 y pronto fue traducida a otras lenguas".

Otro dato de la importancia que tuvieron las relaciones desde su origen, y a vez la relevancia de su estudio en la actualidad, lo encontramos en la siguiente afirmación de Folke Dahl (citado en Baker, 1999: 9):

...rendre hommage au travail du groupe de chercheurs, venus de nombreux pays, qui ont, durant les deux derniéres decennies, transformé notre connaissance de la presse périodiqued'Ancien Régime, et dont le travail oriente l'enquête sur l'histoire du journalisme dans de nouvelles directions [...] allant en longitude de Saint-Pétersbourg à Philadelphie et en latitude de Lisbonne à Cologne, chronologiquement du début du XVIle siècle à la fin du XVIIle, méthodologiquementdu quantitatif au narratologique. Du point de vue génerique, aussi, on aborde une grande variété de média d'information 
politique: le bulletin manuscrit, l'almanach, la gazette, le mercure, le "lardon", le pamphlet, la feuille clandestine...

La rápida difusión e información de estas hojas nos permite deducir que direccionismo y control están ya presentes en los medios de información desde sus inicios. Esto las diferencia de las crónicas y las hace más ambiciosas, puesto que el destino de su lectura no es un a posteriori sino el del presente inmediato. $Y$ es este rasgo de actualidad el que les permite contribuir tanto al cambio como a la permanencia de la ideología imperante en una sociedad. Así lo afirma Carmen Espejo (2012: 103-124) al decir que la regularidad en las publicaciones y la coincidencia de la información con la opinión dan al periodismo, desde estas primeras manifestaciones, la capacidad de influir en las estructuras políticas.

Según Cátedra (1996: 33-64) adoptan parcialmente la retórica de las epístolas de relación o de nuevas, así como la de las cartas de aviso y llama "locura informativa de los nuevos tiempos" al auge que van cobrando a medida que se convierten en un producto a medias entre la carta y el periódico, cada vez más cercanas al concepto actual de periódico.

Manuel Borrego (1996: 137-153) habla incluso de "libro de estilo" en el estudio de un texto del relacionero Andrés de Almansa, en el que critica a Pedro Mantuano por el escrito de la relación: Casamientos de España y Francia y viage del Duque de Lerma llevando la Reyna Cristianísima [...] Doña Ana de Austria al passo de Beobia, y trayendo la Princesa de Asturias nuestra Señora por no haber seguido los aspectos formales en la composición de una relación. Insiste en que “...hablar más o menos de un tema, mencionar las motivaciones de una de las partes y no de la otra, introducir comentarios en un sentido o en otro, no pueden ser considerados actos inocentes...". Esta afirmación, digna de figurar en el libro de estilo de una redacción de hoy, tiene mucho que ver con una declaración de intenciones pues siempre hay algo más detrás de la elección del léxico y la sintaxis. Los libros de estilo, al controlar la expresión, incorporan un criterio para la depuración de elementos informativos.

\section{Leyes para el control de la tipografía}

La actividad tipográfica fue acogida con interés por los Reyes Católicos quienes, sintiendo la responsabilidad del gobierno de los pueblos, vieron que la posibilidad de la imprenta para abaratar y multiplicar los escritos resultaría en beneficio del hombre, en su mejora moral, por supuesto al servicio de las pautas impuestas por los códigos 
éticos y políticos de la época ${ }^{1}$. Como el fenómeno del conocimiento se relaciona y depende de la economía, promulgaron estos reyes decretos por los que liberaban de impuestos a los libros importados y así, en 1480 se legisla: “...quanto era provechoso y honroso que a estos sus reynos se truxesen libros de otras partes [...] y ordenaron que de los libros no se pagase alcabala [...] que de todos los derechos y diezmos y almojarifazgos sean libres y francos los dichos libros" (Reyes, 2000: 772).

No sospecharon los gobernantes en un principio que la invención pudiera salirles respondona, pero cuando esto se produjo pronto encontraron las medidas para intentar acallarla, o aún mejor, someterla, manipularla y convertirla en la fiel aliada de sus intereses. Se fue creando un laberinto de leyes, normas y castigos que coartaban la libertad de la actividad profesional de impresores, encuadernadores y mercaderes de libros. Pero esta maraña de reglas provocó a su vez la dificultad del control de tal modo que esta persecución no pudo impedir la creación de una poderosa opinión pública en Inglaterra, ni la eficacia de las mazarinadas en Francia, ni el nacimiento de un fuerte corporativismo entre impresores ${ }^{2}$.

Y ello, pese a los riesgos que entrañaba. Este párrafo de la pragmática de junio de 1627, firmada por Felipe IV lo deja bien claro: “...no se impriman ni estampen relaciones ni cartas, ni apologías ni panegíricos, ni gazetas ni nuevas, ni sermones ni discursos o papeles en materia de Estado ni Gobierno [...] aunque sean muy menudos y de pocos renglones sin que tengan ni lleven primero examen y aprobación [...] y todo cuanto se hubiere de imprimir, sea con fecha y data verdadera, y con el tiempo puntual de la impresión, de forma que pueda constar y saberse quanto se hace: y lleve y contenga también los nombres del autor y del impresor [...] cualquier impresor o mercader de libros, o encuadernador o librero que no guardare o cumpliere lo que le toca, incurra en pena de cincuenta mil maravedis por la primera vez, y sea desterrado de estos Reynos por el tiempo de dos años; y por la segunda vez se duplique lo uno y lo otro; y por la tercera pierda y se le confisquen todos sus bienes y el destierro sea perpetuo" ${ }^{3}$. Otra ley más que persigue al impresor-librero. Los impresores españoles fueron cautos y mantuvieron en general un medroso silencio ante las decisiones del rey y sus validos.

\footnotetext{
1 “...considerando cuan provechoso y honroso es que se traigan libros de forma que los hombres puedan mediante ellos volverse sabios..." en Ley I. Título XV, libro VIII. Novísima Recopilación de las leyes de España. Pág. 587, del vol. III de V edición de Salvá, Paris, 1854. Recogido por NORTON (1997: 186).

${ }^{2}$ Sin embargo esta tesis del control por parte del poder que se aplicó, y con mucha dureza, en otros estados europeos occidentales no acalló ni distorsionó la opinión pública que se manifestó antes y más pujante que en España. Weill (2007: 23-31) menciona el caso del italiano Annibale Capello al que le cortan una mano y la lengua por falsario y calumniador. En Inglaterra, la Cámara Estrellada ya hace una severa codificación de la censura en 1586 y era admitido que el derecho a publicar noticias pertenecía al rey. Existía la prohibición de publicar acontecimientos del interior salvo los "sucesos" -epidemias, asesinatos, deportes

${ }^{3}$ Novisima Recopilación. Libro VIII, Título XVI, Ley IX. Recogido por REYES GÓMEZ, (op. cit. p. 846).
} 


\section{Juan Gómez de Blas, impresor en Sevilla}

Las relaciones publicadas en los siglos XVI y XVII fueron numerosas y muchos los impresores establecidos en las grandes ciudades europeas y españolas. Sevilla, convertida en el centro económico del Imperio español fue una de ellas. La entrada y el tráfico de las riquezas procedentes de América atraen a la ciudad a gentes de muy diversas procedencias y credos: genoveses, alemanes, cristianos, judíos... y también pícaros y ladrones. Un caldo de cultivo para engendrar noticias de todo tipo, no siempre halagüeñas que, como consecuencia de la censura y sus bien establecidas normas, no pasaban a los papeles...

Y no porque faltaran impresores en la ciudad; Aurora Domínguez (1992) cuantifica en unos 50 los impresores de la primera mitad del XVII. No todos importantes, de ahí que Carmen Espejo ${ }^{4}$ cuestione ese alto número, destacando además que la actividad de algunos es esporádica y escasa. Concentramos nuestro interés en la actividad de Juan Gómez de Blas, que trabaja en Sevilla desde 1633 hasta 1667. No hay muchos datos de su vida aunque sabemos que fue un impresor reconocido en la ciudad. Espejo (2008) lo sitúa trabajando como aprendiz en el taller de Juan de Cabrera, pasando a regentarlo a su muerte. No debió de irle mal pues en 1661 traslada el taller a la calle Génova (Aguilar, 1992: 17-26), actual Avenida de la Constitución, zona en la que se agrupaban las librerías y los talleres de impresión. Desde esa zona vecina y equidistante de los poderes civil y religioso y frecuentada por los vecinos de la ciudad, podía recoger y hacerse eco de lo que se cocía entre el pueblo, del recelo ante la Inquisición, de la corrupción de la cárcel y de la pobreza que desgastaba a la ciudad, del descontento en general, de la "acedia" de la que habla Maravall (1990: 311). Podía. Pero no hay constancia de que lo hiciera.

En este mismo año de 1661 inicia una empresa que va más allá de la publicación de las noticias puntuales de las relaciones y que lo confirma como editor periodístico: imprime una reedición de la Gazeta de Madrid de Fabro Bremundan, y lo hace no limitándose a la simple copia de la madrileña, sino queriéndola convertir en un reflejo de la vida sevillana mediante la publicación de noticias locales. Llega a editar 28 números de la Gazeta, siendo de 1667 la última que lleva su firma (Espejo, 2008).

En 1657 se le había nombrado "Impresor Mayor de la ciudad" y fue el primer sevillano en obtener este privilegio ${ }^{5}$. Este título que sin duda le ofrecía la exclusiva (o al menos la primicia) de los comunicados oficiales lo acredita como impresor de la Catedral, de

\footnotetext{
${ }^{4}$ El más completo estudio sobre la vida de esta Gazeta sevillana es el artículo de Carmen Espejo Cala, "El Impresor sevillano Juan Gómez de Blas y los orígenes de la prensa periodística" (2008).

5 Joaquín Hazañas y la Rúa cita a Luis Begínez de Castilla como último impresor de la dinastía, desde 1778 hasta 1800 (1892: 14).
} 
la Inquisición, de los Cabildos y de los Tribunales $^{6}$, lo pone a partir de ahora al pie de sus obras, casi por completo dedicada a la impresión de pliegos sueltos ${ }^{7}$. Aunque también hace impresiones de libros de las que nos quedan algunas reseñas repartidas a lo largo de su vida de impresor ${ }^{8}$.

Parece ser que la función del Impresor Mayor era trabajar en la publicación de comunicados y resoluciones de las instituciones, numerosas en Sevilla (la Audiencia Real, la Casa de Contratación, el Consulado, la Inquisición y varios e importantes conventos) no siempre coordinadas entre sí. Es lógico pensar que para la realización de estos encargos -que a veces funcionan a manera de incipientes boletines oficiales- se eligiera a alguien buen conocedor de las técnicas tipográficas, de suficiente experiencia en ese medio (no olvidemos que Gómez de Blas había empezado a imprimir en 1633 lo que le da una experiencia de 24 años para cuando obtiene el puesto), capaz de regentar un taller con tres o cuatro operarios y de procurarse los instrumentos necesarios de papel y tintas por lo general de dificil provisión. Nuestro impresor reunía estas condiciones, pero ¿bastaban éstas para hacerle merecedor del cargo? Sin duda se exigía algo más que esta destreza profesional; el cargo, con sus ventajas, tendría que recaer en una persona no desafecta a las corrientes ideológicas imperantes en la época, ni al gobierno central, ni a sus complicados microorganismos, no por localistas faltos de poder. Gómez de Blas poseía sin duda estas características (los temas de sus publicaciones lo confirman) puesto que consigue aunar en su persona los encargos de impresión del Cabildo, de la Catedral, de la Inquisición y de los Tribunales ${ }^{9}$. Y aún puede destacarse otra tendencia del impresor: la de un profesional cuyas

\footnotetext{
${ }^{6}$ Bouza explica el porqué de tal profusión de títulos: “...La Iglesia y la nobleza también recurrieron a la imprenta en la escala específica de sus relaciones con clérigos y fieles de sus diócesis y con los vasallos de sus estados [...], el recurso a la imprenta empezó a hacerse común a la hora de que los distintos poderes entrasen en relación con las comunidades que regían. Pero, al mismo tiempo, también los particulares recurrieron cada vez más a las prensas para dar a conocer sus pretensiones o enfrentarse entre sí, cosa que también hicieron las órdenes religiosas y los cabildos urbanos" (2008: 14).

${ }^{7}$ Es posible que no se trate de una libre elección. García de Enterría propone esta explicación: "Las razones de tipo económico contribuyeron también al aumento impresionante de pliegos sueltos en el siglo XVII [...] La dura política de las autoridades contra el libro puso en graves dificultades económicas a los impresores. Para compensar sus pérdidas recurrieron a la fácil impresión de los pliegos [...] que podrían imprimirse velozmente: 1500 copias en un día; el papel que usaban era de baja calidad y precio. Estos pliegos se podrían vender fácilmente y el dinero obtenido ayudaba a los impresores a hacer frente a la crisis". A esto se unía la práctica entre los relacioneros de copiarse las noticias y reimprimir textos ajenos (1993: 120-130).

${ }^{8}$ En la investigación realizada para mi tesis he llegado a computar 443 títulos (312 entre relaciones y gacetas, más 131 trabajos de otros temas).Que son muchos y teniendo en cuenta la tendencia del lector a deshacerse de los impresos sueltos puede deducirse la gran cantidad que imprimió que le permitió hacer de la imprenta suprincipal modus vivendi.

${ }^{9}$ Hazañas y la Rúa hace esta reseña: “...agregó a los títulos mencionados el de Impresor de la Provincia de Andalucía, del Orden de Nuestro Padre San Agustín, según se lee en el sermón que en las honras de los Duques de Arcos predicó Fr. Juan de Zamora y que imprimió en 1658".Pero no parece que concediera demasiada importancia a este título, pues no lo expone en el colofón de sus relaciones (1892: 133).
} 
publicaciones están al margen de los temas populares de cuyas impresiones viven otros talleres ${ }^{10}$.

Así que Gómez de Blas, que depende del patronazgo civil y religioso, prefiere escribir los textos transmitidos por las diferentes instancias del poder y arrastra a sus lectores a lejanos campos de batalla donde la verificación de la verdad de las victorias no es inmediata. La interpretación de estos vacíos sobre la terrible situación social de la ciudad nos lleva al convencimiento de que acepta su rol social de buen grado y sin duda representa a la persona de confianza que necesitan las instituciones para dar fiel publicidad a su gestión. Tampoco en su gremio debía estar mal considerado pues en los documentos que ofrece Gestoso aparece como participante en la vida de la Cofradía y sirviendo de aval a otros. Su arraigo en la ciudad, en la que trabajó toda su vida, lo muestra su empeño en adscribir a ella a sus herederos.

\section{Datos biográficos y profesionales}

Son escasas las referencias documentales sobre su vida. Leyendo la obra de estudiosos de finales del XIX y XX sobre la historia de la tipografía sevillana hemos encontrado tres referencias de Gestoso y Pérez (1929: 147-149). Una de 1649 en la que aparece como valedor de un arrendamiento: Lej‥ de varios papeles, particularmente respectivos a los capellanes de coro. Tabla 128. Archivo de la Catedral. Otra de 1658 solicitando la devolución de la fianza de una casa: en Colec. de Autógrafos del Autor. (Bib. Colombina). Y una tercera referencia de 1673: solicitud dirigida al Vicario General de la Orden Tercera, presentada por su viuda en demanda de un pago por una cuidada impresión realizada por el hijo, Juan Francisco de Blas. (Of. 13, lib. II de dho año, fol. 592. Arch. de protoc.).

En Hazañas y la Rúa (1892: 46) encontramos los siguientes textos:

En el año de 1661 se trasladó de una casa de la calle de San Acacio a la de Génova, a una casa del Cabildo, en la que vivió hasta 1690. De la nota de este arrendamiento que he visto en el archivo de esta Catedral, resulta que su Cabildo adjudicó en 4 de abril de 1661 una casa de su propiedad, en calle de Génova, a

\footnotetext{
${ }^{10}$ Espejo hace la siguiente afirmación: “...los impresores que detentaron a lo largo del XVIII el privilegio de Impresores Mayores se mantuvieron lejos de los géneros propios del consumo popular [...] y consiguieron una saneada supervivencia gracias a la abundante demanda de trabajo que aún generaban las instituciones". (En "El Romancero vulgar del siglo XVIII en Sevilla: estrategias de producción de los impresores". http://www.lyraminima.culturaspopulares.org/actas5espejocala). Esto, que es válido para el XVIII, también debiera serlo para el XVII aunque lo de la "saneada supervivencia" nos ofrece serias dudas para este siglo pues en los escasos documentos de Gómez de Blas no es raro encontrar quejas sobre las dificultades económicas que tiene.
} 
Juan Gomez de Blas, impresor de la Santa Iglesia, a su mujer Magdalena del Castillo y a su hijo Juan Gomez de Blas, de diez años de edad: de este contrato fue fiador Esteban Morau, maestro impresor en la Magdalena, del que solo esta mención he hallado ${ }^{11}$.

Así como una petición que el hijo presenta a la ciudad, en 1667 solicitando para él la continuidad del nombramiento de Impresor Mayor, acompañado de otra petición firmada por la madre en la que amparándose en el trabajo de toda la vida del padre, avala la seriedad del hijo que "desea servir á V. Sạ. de la forma y con la puntuali-dad que lo hacia el dicho Juan Gomez de blas".

Es obligada mención a una referencia que consta en el manuscrito anónimo Xícara de chocolate contra Torre Farfan y su Templo Panegirico $(1663)^{12}$. Se trata de una burla que se hace a Torre Farfán, sacerdote de la Catedral, animador de justas poéticas y, según él mismo se proclama, autor de muchos de los villancicos que por Navidad imprime Gómez de Blas y por lo tanto en contactos con el impresor. Dice uno de los personajes:

Dígame Vuestra Paternidad: ¿el intento del autor

fue hacer aquí relación o panegírico? Porque con la lisura

de aquella no se casa bien el estilo grandilocuo y arduo,

con los encomios tan encarecidos. A nuestro Juan

Gomez de Blas se cometiera mexor, que con su pie

manco y mano coja las pone pintiparadas... ${ }^{13}$.

Estos son los escasos datos encontrados. De su privacidad, nada; tampoco teníamos certeza de su muerte que situábamos en 1667 pues en este año publica el siguiente impreso: Relacion del feliz viage de la señora Emperatriz, desde el Puerto Final, a Viena

\footnotetext{
${ }^{11}$ El mismo Gómez de Blas deja constancia del cambio en la GAZETA NVEVA DE LAS COSAS MAS notables, que han sucedido a los Padres Redemptores del Orden de la Santsssima Trinidad, Calçados de las Prouincias de Castilla, y Andaluzia, en la Redempcion que han hecho en Arzila, Alcaçar, Zalé, Fez, y otras Ciudades de Africa, sacando 133. Cautiuos Christianos del poder de Infieles. Refierense las guerras ciuiles que padecen los Mahometanos, y la causa de tosas ellas, hasta fin de Março de 1661. (Numero V). en que declara, esta vez no sin cierta satisfacción de "propietario": "Vendese en su casa en la calle de Genova". Repite la fórmula en gaceta no VI. A partir de ahora aunque de vez en cuando cita la calle no vuelve a airear su derecho de propiedad.

12 En MONTERO, J.:http://hdl.handle.net/11441/50349 [consultado 14/04/ 2018]

${ }^{13}$ ¿Se refiere el autor del comentario a una minusvalía real del impresor o es una crítica a lo plano de sus composiciones? En el primer caso esta dificultad podría servir de explicación a la actitud dócil que se le sabe al impresor en su profesión. Pero si critica la simpleza descriptiva de sus relaciones bien debía saber que el margen crítico-literario de tales escritos era estrecho o ninguno, que las más de las veces se escribían sobre plantilla dada por la autoridad, y como hemos aventurado, no era Gómez de Blas proclive a la rebeldía... Sin razones convincentes nos inclinamos por la primera posibilidad.
} 
de Austria y desposorios de sus Cesareas Magestades, celebrados en aquella Imperial Corte domingo 5 de diziembre de 1666. La celebración tuvo lugar en diciembre y un mes más tarde, probablemente en los primeros días de enero del siguiente año se publica la noticia en Sevilla. Así se lee en el colofón: CON LICENCIA / Imprefla en Seuilla, por Juan Gomez de Blas, fu Impreflor mayor. / Año de $1667^{14}$. Las relaciones posteriores salidas de su imprenta ya llevan la firma de su hijo Juan Francisco de Blas.

\section{Localizacion de su testamento}

En el curso de nuestra investigación supimos que los archivos de la parroquia del Sagrario habían sido trasladados a la Biblioteca Colombina y puesto que Gómez de Blas vivía en la calle Génova, perteneciente a la collación de esta iglesia, pensamos que tal vez allí existiera algún indicio al menos sobre su muerte pues dicha parroquia, que había sido inaugurada en 1662, no tenía antigüedad suficiente para guardar archivos de tiempos anteriores (boda, bautizos de sus hijos) que pudieran servirnos. Encontramos en sus legajos un asiento de su funeral, mes de abril de 1667, que transcribimos: ${ }^{15}$

\section{Savado 30}

Iuan Este dia Juan Gomez de Blas
impresor en la calle de Genova
enterrose en San Pablo testo ante
Pedro go Davila albasea doña
Madalena del Castilla su
mujer y el P. fray Juan Pinto de San
Geronimo y Lucas Ruiz.
derechos_
ofrenda CC_
sacristan _
fabrica__
de 30 apenados
novenario por el

\footnotetext{
${ }^{14}$ Se encuentra esta relación, digitalizada, en la Biblioteca de la Universidad de Sevilla con signatura A 111/008(33).

${ }^{15}$ Parroquia del Sagrario. Defunciones, libro 17, pp. 394 oo- 395ro
} 
dicho sacristan 27

encomienda para

el dicho sacristan

fabrica

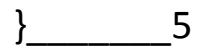

Ahora ya, con la certeza de que había testado y suponiendo que tal acto de había producido poco antes de su muerte, según consta en el asiento de la parroquia sobre su funeral, decidimos indagar en el Archivo Histórico Provincial de Sevilla, en donde tuvimos la fortuna de encontrar su testamento.

\subsection{Transcripción}

Para hacer más fácil la lectura, puesto que se trata de un documento extenso, hemos creído conveniente modernizar la escritura ${ }^{16}$ :

Fol. 443 ro/ .

En el nombre de Dios amén. Sepan cuantos esta carta

vieren como yo Juan Gómez de Blas, impresor mayor desta ciudad de Sevilla y vecino de ella en la collación de Santa María la Mayor, estando enfermo en cama en todo mi acuerdo, juicio memoria y entendimiento natural tal cual Dios nuestro Señor fue servido de me dar y creyendo como creo bien $y$ verdaderamente el misterio de la santísima trinidad y de la eterna unidad Padre, Hijo y Espiritu Santo tres personas distintas y un solo dios verdadero, y en todo lo demás que tiene, enseña y cree y confiesa nuestra Santa Madre Iglesia, catolica romana como bueno y fiel cristiano debe tener y creer y temiéndome de la muerte que es cosa natural a toda viviente criatura, poniendo por mi intercesora y abogada a la sacratísima siempre virgen madre de Dios santa María señora nuestra que fue concebida sin mancha de pecado orixinal desde el primero instante de su ser, para descargo de mi conciencia y salvación de mi alma /

Fol. $443 v$ 은

hago y ordeno este mi testamento en la forma y manera siguiente.

Primeramente ofrezco y encomiendo mi alma a Dios nuestro Señor que la hizo, crió y redimió por el precio infinito de su preciosa sangre y le suplico la perdone y lleve al descanso de su santa gloria que es el fin para donde fue criada.

\footnotetext{
${ }^{16}$ Nuestro agradecimiento al profesor de historia de la Universidad de Sevilla Francisco Nuñez Roldán que amablemente nos ofreció la transcripción.
} 
Y cuando Dios Nuestro señor fuese servido de llevarme desta presente vida, mando que mi cuerpo sea sepultado en la iglesia del convento de San Pablo el Real que es desta ciudad de la orden de santo Domingo en mi sepultura que está en medio de la dicha iglesia que la tengo adquirida con mi dinero como asimismo tengo pagado el entierro en el dicho convento de San Pablo cuyos religiosos en teniendo noticia de mi fallecimiento están obligados a venir a mi casa a decir un responso con cera que han de traer del mismo convento y también tienen obligación de salir al compás del dicho convento a recebir mi cuerpo y si el día de mi entierro fuere ora y si no otro día siguiente se diga por mi alma en el dicho convento una misa de cuerpo presente con diácono y subdiácono cuyas condiciones que en razón de lo referido tiene obligación de hacer y cumplir el dicho convento es en la forma que se contiene y declara en un papel firmado del padre prior/

\section{f. 444 ro}

que entonces era del dicho convento y de otros muchos religiosos el cual tengo en una gaveta de mi escritorio dentro de un zurroncillo y encargo a mis albaceas que luego que yo fallesca lleven el dicho papel al dicho convento de san Pablo para que los padres prior y religiosos lo vean y cumplan en su tenor y forma.

Yten mando que en mi entierro acompañen mi cuerpo veinticinco capellanes con la cruz del Sagrario de la santa Iglesia Mayor desta ciudad donde soy parroquiano y el cura lleve capa y por ello se pague la limosna de mis bienes.

Yten mando que se digan por mi ánima y de mis padres y difuntos.

Y por descargo de mi conciencia y de aquellas personas a quien puedo ser en algún cargo de que no tengo noticia, doscientas misas rezadas, la tercera parte de ellas en la parroquia en que se incluyen la cuarta funeral que le pertenece y las demás repartidas en el dicho convento de San Pablo el Real y en el de san Francisco Casa Grande desta ciudad y otras partes que pareciere a mis albaceas.

Yten mando a las cofradías del Santísimo Sacramento y Animas del Purgatorio del dicho Sagrario /

\section{f. $444 \mathrm{v}$ 은}

a cada una seis reales de vellón.

Yten mando a las mandas forzosas acostumbradas y santo sepulcro de Jerusalén a cada parte medio real con que las aparto de mis bienes- 
Yten declaro que soy hijo lexítimo de Juan Gómez de Blas y de María de Quesada, su mujer, mis padres difuntos vecinos que fueron de la ciudad de Baeza de donde yo soy natural.

Yten declaro que yo casé de segundo matrimonio en faz de nuestra santa madre iglesia católica romana con doña Magdalena del Castillo y Solís viuda que entonces era de Diego de Pinares y al tiempo de contraer el dicho matrimonio traxo a mi poder por hija lexitima y del dicho Diego de Pinares una niña del pecho llamada Teheresa de Pinares a la cual crié y alimenté en mi casa y compañía y la puse en estado de matrimonio con Antonio Gallegos Navarrete y siendo así que paraban en mi poder por bienes de la dicha Teresa de Pinares como tutor que fui de su persona y bienes ducientos ducados de vellón la di de dote al tiempo y cuando casó con el dicho Antonio Gallegos Navarrete más de mill ducados como parecerá por la escritura de dote que pasó ante Diego Ramón de Rivera escribano público de Sevilla a que me refiero y declaro que los réditos de los doscientos ducados de la dicha Theresa que eran diez ducados en cada un año /

\section{f. $445 r$ 으}

se consuman y gastaban y mucho más en vestir y calzar y alimentar a la dicha Theresa de Pinares declárolo así para que en todo tiempo conste.

Yten declaro que deste segundo matrimonio tengo por mis hijos lexítimos y de la dicha doña Magdalena del Castillo y Solis mi mujer a Juan Gómez de Blas de edad de quince años y a doña Juana doncella de edad de catorce años y a doña María Josefa de edad de once años y usando de la facultad que las leyes destos reinos me conceden nombro por tutora y curadora de las personas y bienes de los dichos menores mis hijos a doña Magdalena del Castillo y Solis su madre y pido y suplico a cualquier señor juez ante quien se presentare testimonio desta clausula le diere el dicho oficio y cargo de tal tutora y curadora sin dar fianzas ningunas porque yo la relevo por la satisfacción y confianza que tengo de la dicha mi mujer.

Yten declaro que al tiempo y cuando yo casé con la dicha doña Magdalena del Castillo y Solís mi mujer la susodicha trajo a mi poder por su dote hasta unos dieynueve mil reales como constará por la escritura de dote que pasó ante uno de los escribanos públicos de esta ciudad puede haber diecisiete años poco más o menos yo truje al matrimonio/ 
por mis bienes y capital hasta unos mill ducados como parecerá por el inventario y capital que passó por el mismo tiempo ante el mismo escribano, declarolo así para descargo de mi conciencia y que en todo tiempo conste.

Yten declaro que yo e la dicha doña Magdalena del Castillo y Solis tenemos en arrendamiento de por vidas dos pares de casas que son en esta ciudad en la calle de Genova, las unas en que al presente vivimos y las otras en que al presente vive Lucas Ruiz Gijón que estan asesorias a ellas y lindan con una calleja sin salida en la dicha calle de Génova cuya propiedad es de la fábrica de la Santa Iglesia metropolitana desta ciudad a cierto precio de mrs de renta en cada un año y con ciertas condiciones como parecerá por las escrituras de arrendamientos de vidas que passan ante Ambrosio Diez escribano público de Sevilla y que de las rentas de las dichas casas no debo más que este tercio de mes de abril en que estamos y por cuenta del tengo en una gaveta de mi escritorio algunos vales que se me han de hacer buenos que me han dado en la contaduría mayor de la dicha santa iglesia de obra que he entregado para el gasto de la dicha contaduría los cuales dichos vales se han de descontar en este dicho tercio, declaro así para que en todo tiempo conste.

Yten declaro que yo tengo en arrendamiento por mi vida y otra que nombrare unas casas que/

\section{f.446r으}

son en esta ciudad en la calle de la Sierpe antes de llegar a la calleja de las Mossas en que al presente vive un oficial de hacer frenos que la propiedad de ella es de la iglesia colexial de nuestro señor San Salvador desta ciudad en cierto precio de mrs y gallinas de renta en cada un año y con ciertas condiciones de labores y reparos visitación y penas que se contienen y declaran en la escritura de arrendamientos de vidas que está en el oficio y papeles que hoy usa Diego Ramón de Rivera escribano público de Sevilla a que me refiero. Y usando de la facultad que tengo nombro en la vida que lexitimamente debo y puedo nombrar de las dichas casas a doña Magdalena del Castillo y Solis mi mujer para que suceda en ellas en sus mejoras, demasía y más valor de renta desde el día de mi fallescimiento en adelante con cargo de pagar la renta y señorío y de guardar y cumplir las condiciones de la escritura de arrendamiento de vidas de las dichas casas, declaro que tengo pagadas la renta de maravedís y gallinas hasta en fin del mes de (roto) del año pasado de mil y seiscientos y sesenta y seis, debo mas deste tercero de fin de mes de abril en que estamos. 
Yten declaro que yo tengo en arrendamiento por una vida y otra que nombrare unas casas junto al colegio de san Acasio desta ciudad que son las que yo antiguamente vivía cuya propiedad es del hospital del/

\section{f.446voㅡ}

Amor de Dios desta ciudad en cierto precio de mrs de renta en cada un año y con ciertas condiciones de labores y reparos, visitación, penas y las demás que se contienen y declaran en la escritura de arrendamiento de vidas que de ello hay a que me remito y usando de la facultad que tengo nombro en las vidas que lexitimamente de las dichas casas puedo y debo a doña Magdalena del Castillo y Solis mi mujer para que suceda en ellas y en sus mejoras (roto) desde el día de mi fallescimiento en adelante con cargo de pagar la renta y señorío y de guardar y cumplir las condiciones de la escritura de arrendamiento de vidas.

Yten declaro que de la renta de las dichas casas que estoy debiendo al dicho hospital del Amor de Dios alguna cantidad de maravedís de los ciento y cuarenta y siete reales y dos maravedís que cada tercio se le pagan es mi voluntad que mis albaceas y cualquiera de ellos ajusten cuenta con don Juan del Castillo persona que al presente vive en las dichas casas a quien se las tenga arrendadas en precio de cinco ducados cada mes y lo que de resto del dicho arrendamiento me debiere y se cobrare se entregue luego al mayordomo del dicho hospital del Amor de Dios por cuenta de lo que yo debiera y se reciba carta de pago.

Y para cumplir y pagar lo contenido en este testamento nombro por mis albaceas testamentarios a la dicha doña Magdalena del Castillo y Solis mi mujer, a el padre fray Juan de Pinto relixioso del sagrado/

\section{f.447ro}

orden de nuestro padre san Gerónimo conventual en su monesterio de Buena Vista extramuros desta ciudad de Sevilla y a el dicho Lucas Ruiz Gijón maestro del arte de enseñar a leer e escribir e leer y contar vecino desta ciudad en la dicha calle de Génova y a los cuales y a cada uno insolidum doy poder cumplido en mis bienes para que de ellos puedan tomen y vendan en almoneda o fuera de ella la parte que baste y de su procedido cumplan y paguen lo contenido y que se contuviere en este mi testamento y puedan usar del cargo del dicho albaceazgo aunque sea pasado el término de derecho y mucho más y que yo se lo prorrogo y alargo y cumplido y pagado lo contenido y que se contuviere en este mi testamento en el remaniente que quedare de todos mis bienes raíces muebles $y$ semovientes, deudas, derechos y acciones y otras cuales cuentas y cosas que yo tengo y dejare a el tiempo de mi fin y muerte dejo nombro e instituyo por mis 
lexitimos y universales herederos a los dichos Juan Gómez de Blas, y doña Juana y doña María Josefa todos mis hijos legítimos y de la dicha doña Magdalena del Castillo y Solis mi mujer para que todos ellos hayan y hereden para sí por tercias e iguales partes tanto el uno como el otro con la bendición de Dios y la mía.

Yten declaro que lo que yo debo y a mi se me deben constara por una memoria que dexaré firmada de mi nombre en poder del dicho Lucas Ruiz Gijón mi /

\section{f. $447 \vee$ 은}

albacea que declaro que será cierta y verdadera, mando que se pague lo que por la dicha memoria pareciere que yo debo y se cobre lo que a mi se me debiere.

$\mathrm{Y}$ revoco $\mathrm{y}$ anulo $\mathrm{y}$ doy por ninguno $\mathrm{y}$ de ningún valor ni efecto todos $\mathrm{y}$ cualesquier testamentos, mandas (ilegible) y legados y poderes para testar $y$ otras últimas disposiciones que antes de esto yo haya hecho y otorgado hasta el día de hoy para que no valgan ni hagan fee en juicio ni fuera de el salvo este que mando que valga por mi testamento y ultima voluntad en aquella forma que mejor haya lugar en derecho. Fecha la carta en Sevilla estando en las casas de la morada del dicho otorgante en veinticinco días del mes de abril de mil seiscientos y sesenta y siete años, y el dicho otorgante que yo el presente escribano publico doy fe que conozco lo firmó de su nombre en este registro siendo testigos, Juan Baptista Muñoz escribano de Sevilla, y don Juan Clavijo y Andrés de Quesada y Miguel Gijón y Ygnacio Pando vecinos desta ciudad de Sevilla que estaban presentes y lo firmaron de sus nombres ${ }^{17}$.

\subsection{Análisis del texto}

Esperábamos mucha información profesional de la lectura de su testamento: cómo era el taller, qué maquinaria tenía, cómo lo valoraba, qué resolvía hacer con lo que había sido el trabajo de su vida, quienes y cuántos operarios trabajaban con él... algún indicio de su actividad profesional y personal, que tienen las últimas disposiciones la virtud de mostrar cuánto se ama lo terreno ${ }^{18}$. Nada sobre esto, probablemente porque ya lo ha

\footnotetext{
${ }^{17}$ AHPS P-1282 folios 443ro - 447vo

18 “...si la riqueza se entiende como la abundancia de bienes y cosas preciosas [...] el número de los habitantes de Sevilla que podrían pasar por ricos según sus muebles y ajuares y ropa era muy pequeño [...] si por pobreza se entiende lo contrario, carencia de lo necesario para el sustento de la vida [...] era muchedumbre [...]. A unos les preocupaba la ostentación y a otros la simple satisfacción de las necesidades más primarias del modo más austero y sobrio posible. Así pues los muebles y las ropas de la casa respondían a esa regla" (Núñez Roldán, 2004: 51). Por lo que venimos sabiendo de la personalidad y circunstancia económica de Gómez de Blas nos decidimos a encuadrarlo en este último concepto. Coincidente con la interpretación de Lucien Febvre (2005: 153) quien dice que la modesta ambición de
} 
decidido con su mujer a la que sin embargo ofrece una meticulosa rendición de sus cuentas, dejándola bien informada del haber y el debe de su economía y del reparto a "tercias e iguales partes" entre su hijo y dos hijas (f. 447 ro).

Es la primera página una declaración de fe y una aceptación de la doctrina tridentina, queriendo ahuyentar de él y su familia cualquier sospecha de desviación religiosa. Puede entenderse el interés de asentar esta seguridad ante la extendida idea de que el oficio de impresor tenía tintes de hereje, derivada en parte del origen de la tipografía en los países europeos, de influencia luterana y calvinista ${ }^{19}$. Incluso se pronuncia sobre la aceptación del dogma de la Inmaculada ("...santa Maria señora nuestra que fue concebida sin mancha de pecado original desde el primer instante de su ser" -443 ro${ }^{20}$. No hay constancia de que se pronunciara cuando Sevilla debatía este tema y nos sorprende que lo haga ahora. Volvemos a considerar la posibilidad de relaciones perdidas, pero también el cuidado del testador de asegurar su prestigio y confianza ante las autoridades en beneficio de sus herederos y el deseo ponerse a bien con lo divino cuando lo humano llega a su último tramo.

En las páginas 443 № y 444 ro están sus deseos e indicaciones sobre el ritual de su funeral, misas, limosnas, lugar de enterramiento... en lo que muestra gran preocupación e interés por el bienestar de su alma, aún sin nombrarla. Con esta disposición de su testamento no hace sino repetir una fórmula común en la redacción de los testamentos del XVI y XVII, a modo de plantilla. Sobre el formato de los testamentos, encontramos en Rodríguez de Gracia (1991) la siguiente información:

- La parte dispositiva del testamento se abre con el destino del cuerpo y del alma. El alma siempre se remite a Dios, el cuerpo se destina a la tierra, pues es allí de donde proviene. Al ser todos los testamentos que manejamos anteriores al siglo XVIII, los otorgantes nunca dejan este elemento del ceremonial en manos

los primeros impresores y comercializadores de libros de los siglos XVI y XVII era la de obtener ganancias suficientes para tener un estilo de vida sobrio y vivir decorosamente.

\footnotetext{
${ }^{19}$ Martínez Gallego (2000: 40). Tal vez ayudó este recelo social, a más de las imperiosas necesidades económicas, a la creación de un cierto corporativismo, que si bien no llegó a la regulada organización del gremio, que ya no eran los tiempos, sí produjeron unos estrechos lazos entre los miembros del oficio. Más como prueba que como anécdota, señalamos el frecuente hecho de que la viuda de un impresor volviera a casarse con otro, quien tomaba las riendas del taller asegurando así su continuidad. Era también frecuente que realizaran entre ellos intercambios o préstamos de material y que se ayudaran en la venta de los libros o papeles impresos pues era el caso que a menudo el impresor era también librero y hacían acuerdos para vender en su tienda libros que hubieran salido de talleres otros que el propio. Y por supuesto, el mejor modo de asegurar la continuidad de la empresa era adscribiendo los hijos al oficio por lo que se crearon muy desde el principio verdaderas dinastías de impresores.

${ }^{20}$ García Bernal (2006: 69-83) estudia el fenómeno singular de la proliferación de relaciones de tipo festivo-religioso que se produjo en Sevilla desde las primeras décadas del XVII a propósito de la diatriba teológica de la concepción sin pecado de la Virgen. La ciudad se sumó a la controversia religiosa con pasión de auténtica militancia, bien alimentada por las órdenes de franciscanos y dominicos que mantenían convicciones contrarias, más la jerarquía eclesiástica.
} 
de sus albaceas. Ellos serán quienes estipulen dónde quieren ser enterrados. A partir de 1700 fue frecuente abandonar este ceremonial a la decisión que tomaban los albaceas o los herederos.

- Las misas serían aprovechadas por el alma, como un recurso más para obtener el perdón de la divinidad. Los sufragios no ordenados por el testador y realizados por mandato de los albaceas, sólo se aprovecharán para satisfacer las penas del purgatorio; de ahí que era necesario actuar personalmente, siguiendo los aspectos dogmáticos de la doctrina escolástica.

En páginas 444 vo y 445 ro obtenemos una leve información sobre su origen. Es originario de Baeza, Jaén, y quizá esa procedencia tenga algo que ver con su carácter más reservado que el que se atribuye al sevillano. Queda claro que es minucioso y cuidadoso del dinero, sin duda porque no andaba holgado. Sobre la dote que concede a su hijastra recuerda bien la cantidad recibida así como la otorgada, y tiene en cuenta los gastos de manutención y el montante de los intereses de los años que estuvo a su cargo, pero no la nombra heredera ${ }^{21}$. Su inclusión en el testamento obedece a su deseo -manifiesto en todo el documento- de que las cuentas queden claras ${ }^{22}$. Por sí solos esos números no aclaran si se trata de cantidad sustanciosa o no. Tendríamos que saber qué permitía hacer esa cantidad en esos años para lo que repetimos este dato tomado de Amigo Vázquez (2004: 189-205) que, aunque anecdótico, puede resultar orientativo: "En las celebraciones por la canonización del Rey Fernando, en Valladolid, se imponía multa de 500 ducados a cada capitular que no asistiera a la fiesta de misa y sermón que hace en su santa iglesia el dean y Cavildo desta dicha ciudad". Según esta disposición Teresa sólo habría podido permitirse no asistir a dos misas, aunque lo más probable es que fuera este un castigo ejemplar, dirigido a los capitulares.

En el propio testamento encontramos una pista: el alquiler de la casa perteneciente al hospital del Amor de Dios, sito en la zona de San Acacio, donde tuvo su primer taller, es de 5 ducados al mes.

\footnotetext{
${ }^{21}$ Para la sensibilidad de nuestra épocaparece una referencia muy fría. Pero aclara Núñez Roldán que “...en la Sevilla de los siglos XVI y XVII las relaciones entre los esposos y entre éstos y sus hijos fueron distantes y frías, entendiendo por ello la ausencia de lazos emocionales íntimos, afectuosos y expresivos, tanto en las palabras como en los hechos..." (2004: 126).

22 Núñez Roldán nos ofrece una explicación para ese prurito maníaco de ajustar los centavos a la vez que un apoyo a nuestra certeza de que Gómez de Blas, para lo bueno y lo malo, era un hombre consecuente con el estándar barroco: "Las relaciones exhaustivas de débitos en los testamentos eran realmente reveladoras no sólo de la presión de la conciencia ante la muerte, sino de la extrema confianza en la palabra dada que en vida mantenían los hombres entre sí tanto al pedirse, como al prestarse, como al esperar la restitución, pues todos eran partícipes de una mentalidad reparadora de las deudas y de los males causados en vida..." (2004: 227).
} 
Proponemos otro ejemplo del valor de los 1000 ducados. Mendoza García (2008) estudia una escritura de 1685 en la que se dice que entre la dote que Josefa de Guzmán aportó al matrimonio se contaba un oficio de escribanía en Coín, valorado en 1000 ducados. (Es curioso que la legislación del Antiguo Régimen permitía que una mujer poseyera cargos públicos aunque no disfrutaba del derecho a su ejercicio. Si un escribano quería ceder los derechos a su hijo, nombraba heredera a la viuda "como madre y curadora" del hijo hasta su mayoría de edad, los 25 años). No ocurría así con el oficio de impresión pues son muchas las mujeres que pueden citarse como, al menos, titulares de imprentas en activo ${ }^{23}$, ni tampoco la edad exigida al titular es tan alta; Juan Francisco de Blas tiene apenas 17 años cuando accede al nombramiento.

La respuesta más clara la tenemos en el citado artículo de Rodríguez de Gracia donde nos dice que era frecuente la cantidad de 1000 ducados, entre la gente sencilla, como legado o dote para los hijos.

Insistimos en la sorpresa que produce el desapego de Gómez de Blas ante el futuro de su negocio por el que había trabajado hasta bien poco antes de su muerte, a juzgar por su trabajo impreso. Aunque al dejar libre a su mujer de decidir es evidente que entre ambos hubieran ya resuelto qué hacer con el taller y el futuro del hijo ${ }^{24}$. La decisión ya estaba tomada pues, citando a Carmen Espejo (2008), "en 1662 aparece ya un impreso de Juan Francisco de Blas (véase registro 1699 de Escudero y Perosso)". En cualquier caso, un detalle más del hermetismo de su carácter. Lo cierto es que doña Magdalena parece darse prisa en solicitar el cargo para su hijo, que mantuvo de por vida y que legó a sus herederos ${ }^{25}$ quienes, aunque no en línea directa familiar lo mantuvieron hasta bien entrado el siglo XIX.

\footnotetext{
${ }^{23}$ Para no cansar nos limitamos a citar los nombres de cuatro mujeres que ejercieron como impresoras en Sevilla y Madrid. (Hubo muchas más en Burgos, Valencia, Zaragoza...)

Ana de la Peña, madre de Alonso de la Barrera (1570 - 1572) Sevilla

Brígida Maldonado, viuda de Juan Cromberger (1541 - 1545) Sevilla

Catalina del Barrio y Angulo (1621-1622 y 1633-1651) Madrid

María Quiñones (1628 - 1666) Madrid

http://www.bne.es/es/Micrositios/Guias/Mujeres/mpresoras/resources/docs/Mujeres/mpresoras.pdf [Consultado 14/ 04/2018]

${ }^{24}$ El taller era lo realmente importante en la herencia y lo único sobre lo que podía arrogarse la propiedad, si no del local sí al menos del mobiliario y enseres. Nos remitimos de nuevo a Jaime Moll (2003: 31-38) quien presenta el taller de imprenta como una industria manufacturera que necesita de un capital que viene de alguna de estas fuentes: "o lo aporta el impresor, fruto del ahorro, de la venta de alguna propiedad suya o de la dote de su mujer, o a base de crédito con la garantía del propio taller, que procurará ir amortizando. Otra posibilidad es la continuación del taller heredado de su padre, de su suegro o de la viuda del impresor con la que se ha casado. Son las principales formas de acceso". No sabemos cuál de ellas le sirvió a Gómez de Blas, pero sí cuál prepara para su hijo y por tanto ni menciona ese punto en el testamento.

${ }^{25}$ Como ya se ha mencionado los impresores se enfrentaban a un recelo social, fomentado por las continuas normas de censura que iban apareciendo, que tuvo el efecto de crear estrechos lazos entre
} 
Mucho más interés muestra en la gestión del alquiler y mantenimiento de las casas a

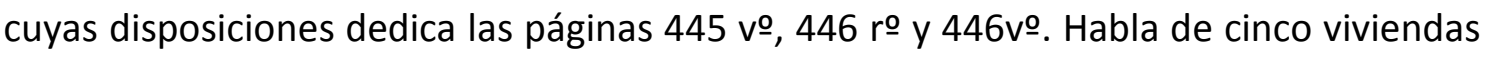
que si bien no son de su propiedad, pues de ellas, dos pertenecen a la iglesia Metropolitana (las de la calle Génova), otra a la parroquia del Salvador, y otras, en Sierpe, frente al colegio de San Acacio (donde tuvo el primer taller) al Hospital del Amor de Dios, las tiene en cesión de por vida, derecho que traslada a su mujer. Probablemente esta cesión en concepto de gajes de su trabajo como impresor de estas iglesias, cuyos pagos no siempre serían muy puntuales.

¿A quién pertenecen las casas? Carmona García (1986) aclara este tejemaneje de las viviendas en su artículo "Caserío y arrendamientos urbanos en la Sevilla del XVII" de lectura necesaria para mejor entender esta parte del testamento y del que entresacamos la siguiente información esencial: la nobleza no se interesó por la compra y posesión de bienes inmobiliarios, no especialmente según avanzaba este siglo que ya portaba el germen de la decadencia de la ciudad. En cambio las instituciones religiosas (la catedral, los hospitales de beneficencia) poseían gran parte del caserío urbano de cuyo alquiler sacaban parte de las rentas necesarias para su supervivencia. El precio se estipulaba por años, lo que simplifica la tarea; además se incluían las gallinas del corral, de coste variable pues se tasaban según el valor del momento en que se cierra el contrato y esta cantidad se sumaba a la cantidad anual que debía entregar el arrendatario, Así aparecen las gallinas, lo que explica el interés por ellas que mostraba Gómez de Blas en su calidad de arrendador, según documento citado por Gestoso de 1649. Su solvencia económica en estos años no parece muy garantizada (no hay que olvidar que es el año de la peste). Solicita que se le levante la responsabilidad de fiador a la vez que pide una demora para que le sea posible recoger el beneficio de la puesta de las gallinas que criaba en el corral de la casa en litigio, cuyos polluelos pondría a la venta. Un detalle menor, aunque importante, que nos muestra a un hombre pendiente de la rentabilidad de las cosas cotidianas al que preocupa la gestión de su taller. Atento también a la de las casas y su gallinero, práctica habitual en los corrales de las viviendas de la ciudad ya que por la bajada del precio del suelo, desde inicios del XVII, era posible la construcción de casas bajas con un amplio corral aprovechado para la cría de animales. Lo que constituía una ayuda a la economía familiar.

Además hay que tener en cuenta que su trabajo de publicación de noticias, su interés de editor, le suponían una inversión no siempre sufragada por la venta de tales impresos lo que llevaba al editor a buscar otros medios de financiación ya que el pago de los Cabildos tampoco debía de ser puntual a juzgar por las reclamaciones

ellos. De ahí la frecuencia de matrimonios de viudas de impresores con otros impresores que tomaran las riendas de la imprenta. 
solicitando se le abonen los atrasos ${ }^{26}$. Y reconozcamos también que estas aves eran manjar preciado en la época si consideramos su valor de mercado. Leemos en Domínguez Ortiz (1983: 22): “...valiendo una gallina cuatro reales de a ocho en plata [...] el carnero a cuatro reales...". No consideremos una historia baladí esta de las gallinas ${ }^{27}$. Estas circunstancias anecdóticas son a menudo el filtro que ayuda a reconstruir una realidad, la parte menos visible de la historia, los indicios que acercan a la mentalidad y al desarrollo de la opinión, que la tipografía ayuda a crear incluyendo o excluyendo la información que a los gestores del poder agrade, a la vez que se practica una simbiosis entre los intereses de las esferas de lo público y lo privado.

Era responsabilidad del inquilino ocuparse del mantenimiento de la finca, cosa que normalmente nadie hacía, por lo que el aspecto del caserío era de pobreza y abandono. Tanto que un procurador de Sevilla en las Cortes de 1623 llegó a decir que "en la ciudad había muchas casas cerradas y sin vecindad, y otras caídas". Vemos sin embargo que nuestro impresor se ocupa de las reparaciones, creemos que con esmero, con un pundonor monetario y esa exactitud en las cuentas que parece caracterizarle. Acaso también por cierto miedo a perder el favor de la autoridad eclesiástica, algo que, porque profesionalmente depende mucho de ella, no le conviene. Así que arregla los desperfectos y conserva las facturas.

No era sólo el descuido de los inquilinos la causa del deterioro ni la mala situación económica; el río con sus crecidas también contribuía a ello, y fueron muy frecuentes las riadas entre 1587 y 1650 que dejaban casas en ruina y solares anegados. Tanto como los desastres del río contó en la ruina la terrible epidemia del 1649 "que cerró el ciclo de expansión que se había iniciado ciento cincuenta años antes [...] y que los

\footnotetext{
${ }^{26}$ No era raro entre los libreros que tuvieran otros negocios. Álvarez Márquez (2007: 48), aunque situada en el XVI (pero si ocurría en tiempos de prosperidad pensamos que con mayor razón en los tiempos más escaso del XVII) destaca la figura de Juan Varela de Salamanca que "además de impresor y librero fue dueño de la tercera parte de la nao llamada Santa María del Águila y de otra llamada Servidora de la Madre de Dios, más otros negocios de diversa índole como alquiler de bueyes y novillos... cueros que mandaba encurtir y luego utilizaría él mismo en las encuadernaciones de sus libros..." Parece que se trata de un negociante a mayor escala mientras que los subarriendos de las casas eran práctica menor pero común en el XVI y XVII.

${ }^{27}$ La historia de las gallinas sobrepasa lo local. Recordemos el famoso "poulet D' Henri IV", testimonio de la importancia que debían de tener estas aves en la alimentación de la población. Sí por supuesto en Francia, que era a finales del XVI (y así siguió durante muchos años), una gran potencia agrícola. El campesino labra los campos y cuida los animales de su corral. Una economía cuya explotación racionalizan "le bon roi Henri IV" y su ministro Sully, creando el mito de que "le labourage et le pasturage estoient les deux mamelles, dont la France estoit alimentée, et ses vraies mines du Pérou", (aunque a la vez el gobierno favorezca la creación de manufacturas de lana y seda). No se sabe a ciencia cierta si el rey pronunció la frase siguiente y en qué términos, pues se repiten varias versiones más o menos parecidas: Se dice que fue en 1600 en una conversación con el duque de Saboya: "Je veux qu' il $n$ ' $y$ ait si pauvre paysan en mon royaume qu' il $n^{\prime}$ ait tous les dimanches sa poule au pot". Hoy plato nacional francés del pueblo y la familia, que, como el cocido castellano, es receta con variantes en cada casa.
} 
testigos de la tragedia calculaban causantes de 130.000 muertos $^{28}$. Hubo derrumbes de casas por abandono, luego solares baldíos que se usaron como huertas.

Todo ello dificultó los arrendamientos e hizo bajar los precios. Se tomó la medida de alquilar de por vida, incluso por una o más vidas, que daba menos dinero a corto plazo pero se aseguraban los ingresos durante más tiempo; se reducían los riesgos y se simplificaba la tarea del arrendador, manera de preservarse un poco la Iglesia en asunto tan terrenal. Esto lleva a la práctica del subarriendo, y es esta la razón por la que Gómez de Blas negocia con varias casas que por su especial relación como impresor están situadas en las mejores collaciones (el Salvador, la Magdalena, la Catedral...) y por lo tanto más caras ${ }^{29}$. Por supuesto había ganancia y especulación en ello. Hay constancia de una casa del Cabildo arrendada en cien ducados, subarrendada a corto plazo por 400 .

Con su habitual prudencia no hace constar en el testamento el dinero que recibe; en cambio refleja el que se debe pagar con la clara preocupación de dejar las cuentas saldadas. Una vez más, y en circunstancia tan extrema como la de la muerte, Gómez de Blas mantiene la línea de cautela que ha caracterizado su vida y el deseo de asegurar la de sus descendientes.

\section{Conclusiónes}

Hemos querido ver al impresor en sus textos, entre los usos y normas en que se desenvuelve. $Y$ de esta lectura destacamos su postura acrítica en un discurso plano y neutro que no cuestionaba la verdad de lo que publicaba, que había identificado su pensamiento al imperante en la época, y en el que puede percibirse un respeto, tal vez temeroso, a la fuerza del poder.

Es común que las vidas se acomoden a las circunstancias y estos escasos datos que proporcionan los documentos muestran el empeño en ello del autor. Su implicación en la vida cotidiana de la ciudad, la participación en los usos de ayuda entre impresores, avalando y siendo avalado según la circunstancia, la relación que tenía con quienes movían la economía de la ciudad, en busca de su propio beneficio sin duda, tanto en el aspecto económico como en el de la facilidad para desarrollar su trabajo que además de la obtención de la noticia requería la obtención, no siempre fácil, del material para

\footnotetext{
${ }^{28}$ El autor la considera "una cifra exagerada pues no tenía la ciudad esos habitantes" (Núñez, 2004: 242).

${ }^{29}$ Carmona García (1986) afirma que estadiferencia no siempre se traducía en una separación de oficios y clases, aunque sí en tendencias: en Omnium Sanctorum, una collación pobre, viven los albañiles mientras que en las collaciones más ricas viven oficios más destacados.
} 
su impresión. Pero los villancicos, sermones y otros textos religiosos que interesaban a la iglesia le facilitaban sin duda temas suficientes. Que le fueran encargados a él también son un claro indicio de su buena fama de creyente, no sospechoso de desviaciones, de lo que con frecuencia eran acusados impresores y libreros.

Sin embargo y según muestra el testamento no consiguió por ello grandes beneficios, ni siquiera holgura económica, pues además de la búsqueda, selección, y a veces traducción de la noticia, el rendimiento del taller no le resultó suficiente y hubo de acudir a la gestión de los alquileres. Dos actividades que se retroalimentaban, pues tanto la una como la otra le hacían publicidad. Pero incluso este último escrito, su testamento, le sirve de lienzo que cubre lo que no conviene decir, procurando la continuidad de lo conseguido para sus herederos. El diálogo con este documento nos ha mostrado la cotidianeidad de Gómez de Blas, una vida más, de entre la gente corriente.

\section{Referencias bibliográficas}

AGUILAR PIÑAL, F. (1992): "El Impresor Mayor de la Ciudad", en Temas sevillanos (Primera serie). Sevilla, Universidad, pp.15-26.

BAKER, K. M. (1999): Introduction a Gazettes et information politique sous l'Ancien Régime. Publications de l'Université de Saint-Étienne.

BORREGO, M. (1996): "El libro de estilo de las relaciones del siglo XVII" en Las relaciones de sucesos, relatos fácticos, oficiales y extraordinarios. Besançon, pp. 137-178.

BOUZA, F. (2008): Papeles y opinión. Políticas de publicación en el Siglo de Oro. CSIC, Madrid.

CARMONA GARCIA, J. I. (1986): "Caserío y arrendamientos urbanos en la Sevilla del siglo XVII". Archivo hispalense. T. 69, № 210, pp. 3-28.

CÁTEDRA, P. (1996): “En los orígenes de las epístolas de relación" en Las Relaciones de Sucesos en España (1500-1750), Unv. Alcalá de Henares (pp. 33-64).

DELGADO CASADO, J. (1996): Diccionario de impresores españoles (siglos XV-XVII). (Madrid: Arco/Libros, n. 345). 
DÍAZ NOCI, J. (2001): "Historia del periodismo español en el siglo XVII: Un estado de la cuestión". Comunicación presentada al I Congreso Ibérico de Comunicación. Málaga, mayo de 2001. http://www.ehu.es/diaz-noci/Conf/C25.pdf

DOMÍNGUEZ GUZMÁN, A. (1992): La imprenta en Sevilla en el siglo XVII (catálogo y análisis de su producción) 1601-1650, Sevilla, Universidad de Sevilla.

DOMÍNGUEZ ORTIZ, A. (1983): Sociedad y mentalidad en la Sevilla del Antiguo Régimen. Biblioteca de Temas Sevillanos. Sevilla, Servicio de Publicaciones del Ayuntamiento.

ESPEJO CALA, C. (2008): “El impresor sevillano Juan Gómez de Blas y los orígenes de la prensa periódica. La Gazeta Nueva de Sevilla (1661-1667). Zer. Vol. 13, núm. 25, pp. 243-287.

- (2012): “Redes europeas de comunicación en la Primera Edad Moderna. Un nuevo marco de interpretación para el nacimiento del periodismo" en Roger Chartier y Carmen Espejo: Comunicación y propaganda en el Barroco. Madrid. Marcial Pons, pp. 103-124.

- (2006): "El Romancero vulgar del siglo XVIII en Sevilla: estrategias de producción de los impresores. En Cátedra, P. M. (ed.) La Literatura popular impresa en España y en la América colonial. Formas \& temas, géneros, funciones, difusión, historia y teoría. Salamanca: SEMYR e Instituto de Historia del Libro y de la Lectura, pp. 425-436. http://hdl.handle.net/11441/25625 [consultado 14 / 04/ 2018]

GARCÍA BERNAL, J. J. (2006): El fasto público en la España de los Austria. Sevilla, Secretariado de Publicaciones.

GARCÍA DE ENTERRIA, M. C. (1992): "Lectura y rasgos de un público popular" en Edad de Oro, XII, pp. 120-130.

GESTOSO Y PÉREZ, J. (1929): Noticias inéditas de impresores sevillanos. Sevilla, Gómez Hnos.

HAZAÑAS Y LA RÚA, J. (1892): La imprenta en Sevilla. Ensayo de una historia de la tipografía sevillana y noticias de algunos de sus impresores desde la introducción del arte tipográfico en esta ciudad hasta el año de 1800. Sevilla, Imprenta de los Tribunales.

MARAVALL, J. A. (1990): La cultura del Barroco. Análisis de una estructura histórica. Barcelona, Ariel.

MARTÍNEZ GALLEGO, F. A. (2000): "Las ceremonias de la información y la forja del príncipe en la España moderna. Debates entre la representación del poder y el 
poder de la representación". En Espejo C., Romero Acosta A. et al. (eds.), Propaganda impresa y construcción del Estado moderno contemporáneo. Sevilla, Alfar, pp. 27-57.

MENDOZA GARCÍA, E. M. (2008): “Alianzas familiares y transmisión de oficios públicos: los escribanos de Málaga en el siglo XVII", Nuevo Mundo, Mundos Nuevos [en línea] http://nuevomundo.revues.org/28582 [consultado 14 / 04/ 2018]

MOLL, J. (2003): "El taller de la imprenta". En Infantes V., Botrel, F. y otros (eds.), Historia de la edición y de la lectura en España.1472-1914. Madrid, Fundación Germán Sánchez Ruipérez, pp. 31-38.

MONTERO, J. (2013): "Xícara de chocolate contra Torre Farfán y su Templo Panegírico (Sevilla 1663)", Revista de Manuscritos literarios e investigación, no 13 http://hdl.handle.net/11441/50349 [consultado 14/04/ 2018].

NORTON, F. (1997): La imprenta en España, 1501-1520. Madrid, Ollero \& Ramos

NÚÑEZ ROLDÁN, F. (2004): La vida cotidiana en la Sevilla del Siglo de Oro. Sevilla, Silex.

REYES GÓMEZ, F. (2000): El libro en España y América. Legislación y censura. Siglos XVXVIII. Arco/ Libros. Madrid, (Vol. II, pág. 772: Novísima Recopilación...libro VIII, título XV, Ley I)

RODRíGUEZ DE GRACIA, H. (1991): "Análisis de algunos inventarios y testamentos toledanos", Real Academia de Bellas Artes y Ciencias Históricas de Toledo, pp. 121-146.

http://www.realacademiatoledo.es/files/toletum/0026/toletum26_rodriguezana lisis.pdf_[consultado 14 / 04/ 2018].

WEILL, G. (2007): El periódico. Orígenes, evolución y función de la prensa periódica. Comunicación Social. Sevilla-Zamora. 